\title{
Teacher and Student Attitudes to IELTS Writing Tasks: Positive or Negative Washback?
}

\author{
Malcolm David Lewthwaite \\ United Arab Emirates University
}

\begin{abstract}
The International English Language Teaching System (IELTS) examination in Academic English includes two writing tasks: summarizing information from a graph or chart, and writing a short essay to support a position on an issue of opinion. The aim of this small-scale exploratory survey was to find out from teachers and students their attitudes towards the usefulness of, and preparation for, the two IELTS writing tasks. 'Usefulness' and 'impact/washback' are components of test validity, thus eliciting responses (via questionnaires) from 2 major stakeholders (teachers $n=17$, students $n=36$ ) in this highstakes benchmark exam would provide information about perceptions of validity. The results indicate that both IELTS task one and task two are perceived by teachers and students as having a positive effect on class-based writing skills and bearing a reasonable relationship with skills needed at faculty level. Lack of usefulness was reported mainly by students in the Sharia and Law and Business faculties.
\end{abstract}

\section{Introduction}

In 2004 the United Arab Emirates University (UAEU) introduced the International English Language Testing System (IELTS) exam as the major benchmark examination for students proceeding to undergraduate level studies. The decision was made after long deliberation and with the understanding that any high stakes gate-keeping exam would have a wide impact (or washback) across the University's programmes. It was anticipated that the introduction and influence of such an exam would reach across many areas of the educational process - not only affecting teachers, teaching and learners but also shaping curriculum design, material resources, staff resourcing, course delivery and the attitudes of various stakeholders. Such a wide and profound influence has - anecdotally at least - been the case. This exploratory study focuses on how the introduction of the IELTS writing exam has impacted on two of these areas, namely the attitudes of teachers and learners. In particular, I will explore staff and student perceptions of, and attitudes towards, the usefulness of the IELTS writing exam not so much as a benchmark exam but in preparing candidates for university level studies in an English medium university.

For the purposes of this report, washback is simply defined as the impact or influence of testing on teaching and learning, especially in the classroom. Washback studies are a relatively new phenomenon and, as ever, researchers state that 'more research is needed in the area' (Spratt, 2005:27; IELTS, 2007). Forthcoming studies (Davies, 2007; Green, 2007) also indicate the on-going interest in this area. My own particular interest (and perhaps bias) comes from teaching IELTS-oriented courses as well as being an IELTS Examiner Trainer.

The focus of the study is on the perceptions of teachers and students involved in the IELTS writing test. One reason for this is that studies indicate that the attitudes and perceptions of the candidates are highly influenced by the teacher (Spratt, 2005). It is natural, and in many cases appropriate, that 
students are somewhat apprehensive of a benchmark exam - but it is the teachers' attitudes to a particular exam, and the range of activities that they use to prepare for it, that will be a major determiner of the balance of positive and negative washback in the classroom.

\section{Social / Educational Context}

The nature of any benchmark exam at a state university must, of course, fulfill the general expectations and specific learning outcomes established by the Ministry of Higher Education. The introduction of the IELTS exam itself can be seen in the context of the ministry's aim to educate and prepare its university students for operating in an international environment with an international language and, with particular respect to the writing module, to be competent in written academic and professional communication - both of which require 'critical thinking and expression'. Thus, in his UAEU commencement address (September, 2006), the minister of Higher Education, Shaikh Nahayan Mubarak Al-Nahayan, underlined the need to infuse critical thinking skills across the curriculum. All university courses, including writing courses, need to help students meet the requirements of an international knowledge economy. Similarly, other voices in the region have called for critical thinking, 'not relying too much on references and authorities; rather authorities must be criticized, challenged and questioned" (Al Belehi, 2006), nourishing a 'culture of writing', with writers encouraged to find their own voice.

If, broadly, 'being critical' entails perspective taking, then critical writing would entail the writer being able to generate and express multiple perspectives or, if taking one point of view, providing coherent reasons for doing so. To elicit appropriate perspective taking, test writing prompts (for any international exam such as IELTS) would need to ask candidates to respond to issues and changes in social and economic domains. Candidates who are able to respond adequately by describing, summarizing, interpreting and justifying opinions on international social and economic events, ideas and trends are presumably on the way to becoming literate in English and 'survivors' in the university and wider world.

In this context, IELTS writing examination prompts that invite discussion on global concerns (but which can be applied to the local scene) would have face validity and not only reflect society-wide needs but also presumably have a positive influence on curriculum goals and content. Topics such as the pros and cons of multi-national / international business, the social and environmental impact of mass tourism, improving transportation systems and driving, assessing environmental quality, describing and evaluating the changing roles of men and women and the like, seem to address the macro-context of exam impact and, as such, relate to exam validity. Writing courses and exams such as IELTS with prompts that require learners to support personal opinions and to give explanations or reasons for such, may be seen to play some part in pushing the critical educational practices as required by the ministry and useful preparation for university and modern society; but do teachers and students think that this is happening?

\section{Literature Review}

\section{Positive and Negative Washback}

Exam-driven ESL courses have often had a bad press. In some cases studies suggest that the curriculum is narrowed to those areas to be tested with often a loss of balanced integrated skills work (Read and Hayes, 2003) and a restriction in types of (usually teacher-prepared / authentic) materials to a heavy 
dependency on practice exams. In addition, the content areas of the exams, e.g. units on global warming, can also be emphasised at the expense on more basic language skills such as grammar. Some courses observed by Alderson and Hamp-Lyons (1996) were characterised by 'teaching to the test' and high dependence upon a given text-book ('text-book slaves'), with the result that teachers do not prepare and plan such classes as carefully as non-examination classes. They also found in a observational study that exam classes spend much less time on pair and group activities (e.g. jig-saw communicative work), that there was less turn-taking and that that teachers talk more than in non-exam classes. However the reasons for why there is less interaction in these classrooms is not clear - is it the exam per se, or is it because teachers believe this is the best way to prepare for exams?

At the same time the literature reveals a great diversity as to how teachers actually teach ESL examdriven courses. In one writing reform project teachers reported that a new gate-keeping assessment influenced their methodology, allocation of time and focus on learning activities in both beneficial and negative ways (Cheng et.al, 2004). In another study some exam classes were characterized by independent and inventive approaches and, in some at least, indicators such as use of pair work, turn taking, laughter and new approaches were at least as much in evidence as non-exam centred classes (Alderson and Hamp-Lyons, 1996). High stakes testing - along with associated educational innovation can, if certain conditions are met, provide not only positive motivation for improving teaching practices but also shape and attract teachers' pedagogical practices in desirable ways (Chapman and Snyder, 2000). It can only be concluded that the nature and extent of washback on teaching methods seems to vary depending on the teacher and the context.

With regard to attitudes of teachers and students towards high stakes ESL exams, studies indicate a range of rather negative feelings arising from the exams. Cheng, (1998, cited in Spratt, 2005:17) reports that students showed mixed feelings towards a high stakes exam, recognizing that it pushed them to work hard but feeling that it was not an accurate reflection of their study or did not relate specifically to their future study needs. While students and teachers saw the benefits of having, in this case, an oral component to the exam, both felt high anxiety. In particular, most teachers strongly resented the time pressure they felt in teaching to the exam. A contrasting finding was that of Read and Hayes (2003) who report overall 'positive attitudes about IELTS amongst teachers and strong motivation amongst learners'.

This brief survey of the literature suggests that there is no automatic relationship between the use of an exam in a programme and washback of either a positive or negative variety. As Spratt (2005:21) concludes in her survey of washback research, the various studies show that other factors, particularly the teacher (the most consistently mentioned agent of influence), are more often what determine the kind of washback that exists in a classroom. These factors include teacher beliefs, attitudes, educational level and experience, and personalities. "It can be concluded from the studies that washback is not inevitable and also that it is malleable. This conclusion puts the teacher in the driver's seat in some important ways..." (p. 23). Finally, studies report that a range of stakeholders, particularly teachers and students, see the necessity of having some international gatekeeping exam but feel the tension of having to deal with the time pressure in preparing for the exam and within the exam itself (Coleman et. al. 2003; Spratt, 2005).

\section{Washback and validity}

In this section I raise two points regarding exam validity. Firstly, an important part of washback and exam validity is whether the nature of the exam spawns a course and a skills focus that fit the larger educational goals. It is necessary not only to align the curriculum to the test, but also to demonstrate

Lewthwaite, M.D. (2007). Teacher and Student Attitudes to IELTS Writing Tasks: Positive or Negative Washback?. Learning and Teaching in Higher Education: Gulf Perspectives 4(2). 
that the test integrates into the educational system and improves learning: "A systematically valid test is one that induces in the educational system curricular and instructional changes that foster the development of the cognitive skills that the test is designed to measure" (Fredericksen \& Collins, 1989, in Cheng, 1997). Does the IELTS writing exam contribute to the espoused goals of expressing critical thinking? If teachers and students report that the exam / course pushes critical and independent writing then it is assumed the washback is positive.

Another part of validity is whether the writing tasks, and more importantly the skills needed to produce them, are similar to those candidates will need at university. The validity/authenticity of writing task 2 (the opinion essay) was explored by Moore and Morton (1999) in comparing the task items with a range of undergraduate and post-graduate assignments. The tasks were compared in terms of four dimensions: genre, information source, rhetorical function and object of enquiry. Overall, while it was found that the genres of this task were similar to those of university tasks, the other categories were very different. IELTS tasks required more use of prior knowledge than did university tasks; they had more limited rhetorical functions (an emphasis on hortatory at the expense of other functions such as explanation, comparison, summarisation) and focused much more on 'real world' contexts compared with the greater emphasis on abstract ideas in university tasks. It was speculated by Moore and Morton that task 2 may be more akin to public non-academic genres (newspapers, magazines) than characteristic of university assignments. Balancing this finding was their survey of university staff who reported being favourable towards task 2 and to the nature of language teaching they imagined students would receive in preparing for it. Lecturers also noted a fundamental difference between university tasks which focus on the careful use and evaluation of many sources, and IELTS's focus on opinionated styles. This difference also was noted by candidates, who nevertheless still felt the task was useful for university study (Merrylees, 2003). Having two different writing tasks was seen by lecturers and test-takers as a benefit as it increases the possible generalisability; if they have little background in one, they may be able to demonstrate greater competencies in the other.

\section{Method Of Study}

For this small-scale exploratory action-research a questionnaire (see Appendix 1) was designed and sent out with 7 questions to teaching staff at two programmatically related sections of the UAE University's Communications (English) Unit (UGRU) namely the pre-faculty preparatory programme and the faculty-based adjunct English for Specific Purposes (ESP) unit which teaches writing to undergraduate students. Seventeen questionnaires were completed from the 20 sent out (to all involved in the writing programme) at UGRU's men's campus, and information from an UGRU 'focus-group' discussion on exam washback (led by Mr Ryan Sundlie in November 2005) in which another 6 participated, was also used. In other words, viewpoints were gleaned from around $75 \%$ of the English lecturers at the men's campus, most of whom had a reasonable idea of the various writing tasks required in the undergraduate courses. Semi- formal interviews were also conducted with 3 teachers from ESP in order to glean further qualitative information and to compensate for the low response rate from this unit (only 4 responses from 26 questionnaires sent out). Further, an adapted form of the questionnaire (See appendix 2) was administered to 36 Level 3 (final pre-university level, intermediate to upper intermediate) writing students that I taught. Thus, a total of 53 questionnaires were returned from lecturers and students. In sum, both samplings were 'accidental'.

In the following section the discussion will follow the 7 questions of the questionnaire (shaded) present the statistical results in a table and then integrate the responses of the writing teachers (from both pre-

Lewthwaite, M.D. (2007). Teacher and Student Attitudes to IELTS Writing Tasks: Positive or Negative Washback?. Learning and Teaching in Higher Education: Gulf Perspectives 4(2). 
university and undergraduate writing courses) and students into the report. This is followed by a discussion of the findings.

\section{Findings}

\section{IELTS writing task 1 (summarizing from a graphic) and writing skills for undergraduate level}

\section{(a) Teachers' views on Task 1}

Teacher Questionnaire Question 1: The IELTS Task 1 question asks candidates to summarise a graphic (chart, table, flow chart etc). I agree /disagree that there is a reasonable correspondence between the skills needed for this and needed for writing requirements at faculty level.

Table 1: Teachers' Views on Task 1

\begin{tabular}{|l|l|l|l|l|l|l|}
\hline & $\begin{array}{l}\mathbf{1} \\
\text { Strongly } \\
\text { agree }\end{array}$ & $\mathbf{2}$ & $\mathbf{3}$ & $\mathbf{4}$ & $\mathbf{5}$ & $\begin{array}{l}\mathbf{6} \\
\text { Strongly } \\
\text { disagree }\end{array}$ \\
\hline $\begin{array}{l}\text { Number of } \\
\text { teachers } \\
(\mathbf{n}=16)\end{array}$ & 5 & 7 & 1 & 2 & 1 & 0 \\
\hline
\end{tabular}

The great majority of both teachers and students stated they agree that learning to write for task 1 corresponds to writing skills needed in university study. Teachers in the main noted that the exam required test-takers /students to engage in 'higher-order thinking', that is, to discriminate between the most important and less relevant data, to group and categorise similar trends or information, to synthesize or summarise statistics, numbers or graphic information and to use concise (and nonrepetitive) language in doing so. It was assumed that this sort of task would be relevant whether studying in Engineering, the Sciences, Social Sciences and even Humanities. Some noted that it might not be directly relevant to those studying Sharia and Law because both the taught and examined part of the course is in Arabic, and that more research was needed to explore particular writing needs of each faculty. Most agreed with one respondent's comment that task 1 required the skill 'to quickly identify and select appropriate information and was [generally] transferable to all future writing requirements' and 'understanding tables, charts and graphs in text-books could prove useful in their presentations' as well. Another added it would be a useful introduction to a type of academic register.

Even if some specific tasks seem outside students' immediate interest and schemata - for example one teacher doubted that many students would need to describe a process such as making sugar beet (as in the class text) - it is likely that summarising a process is useful in a range of academic and daily contexts, whether in law, social sciences, medical science, or writing a family letter describing a move to new country.

It was mentioned by an ESP teacher (himself teaching writing specifically for Engineering students) that it would be fairer to give subject specific topics for candidates entering into different faculties rather than the generic topics of IELTS task 2. However, even though it is unlikely that such generic topics are given in most university subjects, keeping to cross-disciplinary topics - rather than giving writing prompts suitable to, say, health sciences or social sciences, arts and so on - does seem a reasonable compromise of authenticity, given that it would be unfair to be subject-specific. Clapham's (1996) 
comprehensive study of IELTS Reading also found a subject-specific approach to be impractical and unnecessary.

Several teachers mentioned the unrealistic time limit of (recommended) 20 minutes for task 1 . While it might reflect one type of university writing - writing exams under time constraints - it was unclear whether this was helpful to another major form of university writing, that of research activity. Notwithstanding some down-sides, the teachers' attitudes towards Task 1 were overwhelmingly positive. What about the students' views?

\section{(b) Students' views on Task 1}

Question 1: Learning to write for IELTS task 1 will help you with your writing in the faculty. Agree / disagree?

Table 2: Students views on usefulness of Task 1

\begin{tabular}{|l|l|l|l|l|l|l|}
\hline & $\begin{array}{l}\mathbf{1} \\
\text { Strongly } \\
\text { agree }\end{array}$ & $\mathbf{2}$ & $\mathbf{3}$ & $\mathbf{4}$ & $\mathbf{5}$ & $\begin{array}{l}\mathbf{6} \\
\text { Strongly } \\
\text { disagree }\end{array}$ \\
\hline $\begin{array}{l}\text { Number of } \\
\text { students } \\
(\mathbf{n}=\mathbf{3 6})\end{array}$ & 14 & 11 & 3 & 2 & 3 & 3 \\
\hline
\end{tabular}

Overall, students saw the benefit of learning task 1 writing skills and understood the reasons for it being part of the examination requirements, although the strength of usefulness depended on their anticipated faculty. Typical comments include: 'Strongly agree...because it helps me when I study or reading because it summarise the information... because in my faculty [Engineering / Business] I will face graphs and charts and it's also useful for my career'. The ability to transfer the skills is suggested in the comment "Writing [task 1] help us to describing the pictures and help us to give an explanation for any issue' and 'very good all my life'. Others emphasised the useful vocabulary they learned. A lower ability student agreed 'because this new words will help the student', while some noted it was easier than task 2 , possibly because 'it help me to write fast'.

A strong exam washback effect is reflected in a handful who responded along the circular lines ' strongly agree because everyone wants to know how to write for IELTS, that means to pass and it will help us in the future and in faculty and in our jobs'. While a few students strongly disagreed saying ' my major is Sharia and Law and we don't need English in my faculty... we don't need a chart or a table', overall, it is striking that both teachers and students have a similar positive belief about the usefulness of task 1 type questions.

\section{IELTS writing task 2 (essay) and writing skills for undergraduate study}

Question 2: Task 2 asks candidates to argue a point of view to develop an position ('to what extent do you agree or disagree') or outline advantages and disadvantages with some social, environmental, technological or other value position. I agree /disagree that there is a reasonable correspondence between the skills needed for this and for faculty writing tasks. (Consider that IELTS candidates need to discuss issues, construct an argument with plentiful relevant ideas and evidence and use appropriate paragraphing, style and format).

Table3: Teachers' views on correspondence of Task 2 skills to University Writing

\begin{tabular}{|l|l|l|l|l|l|l|}
\hline & $\begin{array}{l}1 \\
\text { Strongly }\end{array}$ & 2 & 3 & 4 & 5 & $\begin{array}{l}6 \\
\text { Strongly }\end{array}$ \\
\hline
\end{tabular}

Lewthwaite, M.D. (2007). Teacher and Student Attitudes to IELTS Writing Tasks: Positive or Negative Washback?. Learning and Teaching in Higher Education: Gulf Perspectives 4(2). 


\begin{tabular}{|l|l|l|l|l|l|l|}
\hline & agree & & & & & disagree \\
\hline $\begin{array}{l}\text { Number of } \\
\text { teachers } \\
(\mathbf{n}=16)\end{array}$ & 6 & 8 & 1 & 1 & 0 & 0 \\
\hline
\end{tabular}

Question 3: What similarities and /or differences can you see between the IELTS timed writing tasks (and preparation for) and writing tasks at faculty level?

\section{(a) Differences (implicitly T2 not so useful)}

A number of teachers identified that this task is 'non-academic' in the sense that a personal opinion was asked for and respondents are not able to, and not expected to, draw on empirical evidence, statistical data or the academic expertise of published material. One noted; 'academic writing takes more time (weeks) for thorough reading, referencing etc'. Another recognised the need for the student to make parallel progress in research report writing; 'prior knowledge may facilitate the speed of completing a task, but it is also important that any individual recognise their limitations in any subject area and research the information needed (a major goal of a college education)'. It was suggested that with so much emphasis on the IELTS timed writing exam, and with the demise of the portfolio assessment component - and with such portfolios likely to provide positive preparation for faculty study projects - a negative washback effect was in play for this particular skill.

Various faculties would expect different styles and formats of reporting research and ideas. It was wondered how many universities and faculties nowadays have timed writing exams and the extent that writing assignments now utilise word processing rather than hand 'This task is more similar to school exam writing'. One suggestion was that $\mathrm{T} 2$ writing would require the candidate to read / research a given booklet in order to answer the question.

Some teachers were not sure the extent that $\mathrm{T} 2$ required objectivity or at least presenting a balanced view, or the extent it was better to take a stand without reference to alternative points of view. It was felt by one that even if there were differences, the 'development of a point of view and defence of it is vital to student intellectual development... students will benefit in the long run from the IELTS experience - regardless of differences they will experience within their faculties (in writing assignments)'.

Differences in genre were seen. One respondent in particular saw some sharp differences between global writing exams and college level writing. 'University courses expect descriptive observation, analysis and explanation rather than the one-sided approach of 'agree /disagree'... the types and content of questions are different, the resources of information and the rhetorical expectations of the response are all a big contrast...'

However, even though it was wondered how common argumentative /opinion essays are at undergraduate level (except maybe for a creative writing course) the process of organising and expressing ideas in coherent ways on broad social and environmental topics was generally seen as useful.

\section{(b) Similarities (implicitly T2 useful)}

Similarities given between UGRU /IELTS/ Faculty writing included the need for logical progression of ideas, paragraphing, clear expression and suitably academic and / or topic related vocabulary 
The majority of teachers agreed (some strongly) that this sort of writing would be both a useful discriminator between students who are likely to write well at university and also an indicator of those who had sufficient cognitive skills to survive at university. In this light it was suggested that 90 rather than the 60 minutes would allow time for more considered and edited responses and thus more accurate judgments about the suitability of a candidate for degree study to be made.

It was stated that this type of opinion task in 'non-academic' language seems realistic and appropriate as it is an exam not only for those already inducted into the skills and language of academic research but also for those [at least those requiring a band score of 5 or 6 ] just entering, suitable and accessible to those in between High School and University. The general feeling expressed was that unless IELTS or other exams were made for discipline specific modules such as Engineering sciences, Biological Sciences, Humanities and Law etc. then it is hard to see any alternative to measuring writing skills apart from through some generic rubric that gives candidates from all sorts of backgrounds an equal writing field.

Further to this, task 2 responses were also seen as an indicator of those who would have the ability to cope with university social life in the first year. It was suggested that if someone could not engage and express thoughtful responses to Task 2 questions then it would be unlikely they would benefit from most university environments. Because T2 questions seem to reflect current knowledge and life (issues in broad society, not so much the sharper focus on such topics in the academic disciplines) then it was assumed that those who had difficulty in generating related ideas in a social context would have even more difficulty in writing about them. Similarly, those who were able to write about such topics would have the base skills to research and write more on more specific discipline related topics. In other words, it is suggested that teachers felt that there was not only topic related validity to task 2 but also some predictive validity in the sense that those who produce a good answer to T2 under time pressure would be able to produce even better writing with the relative 'leisure' of a research assignment. Whether this is the case or not only longitudinal and other research can find out, but the teachers' positive attitude to task 2 is clear.

A strength of task 2 is then, ideally, that it allows the writer, in writing 'to the educated public', to use local and global knowledge. While writing an opinion is not, maybe, common place in faculty writing it can nevertheless be an important element in the educational and personal growth of an individual by allowing the writer a voice - as some students mentioned - and to express their own preferences and to draw upon their own cultural and linguistic experiences as a resource. In the wider perspective, in this way, writing teachers can be seen as participating in the required educational changes.

A brief analysis of task 2 shows it is the nature and quality of ideas that is valued. The task 2 prompt itself values and elicits the writers 'voice' to the extent that they can draw on personal experiences and personal knowledge to exemplify and support a position or argument. In fact top marks can only be awarded if the writer has expressed a clearly identified and well-supported position. A clear example of this is seen in a the awarding of an 8 ('very good writer') to a writer who has, according to the IELTS senior examiner, 'maintained a clear position throughout, main ideas are presented and well-supported, apart from some over-generalisations' (IELTS Scores Explained, 2006). It is evident from the criteria that to go to the next and highest level ('Expert User', a 9), the writer's position would have to be even more 'fully extended and supported'.

\section{(c) Students' views}

Table 4: Student views of the usefulness of Task 2

1

1

2

3

\begin{tabular}{|l|l|}
4 & 5 \\
\hline
\end{tabular}

5

6

Lewthwaite, M.D. (2007). Teacher and Student Attitudes to IELTS Writing Tasks: Positive or Negative Washback?. Learning and Teaching in Higher Education: Gulf Perspectives 4(2). 


\begin{tabular}{|l|l|l|l|l|l|l|}
\hline & $\begin{array}{l}\text { Strongly } \\
\text { agree }\end{array}$ & & & & & $\begin{array}{l}\text { Strongly } \\
\text { disagree }\end{array}$ \\
\hline $\begin{array}{l}\text { Number of } \\
\text { students } \\
(\mathbf{n = 3 4 )}\end{array}$ & 9 & 7 & 11 & 3 & 3 & 1 \\
\hline
\end{tabular}

Again, overall, students had a favourable understanding of the rationale of Task 2 . These types of question are seen as relevant and helpful to their growth as individuals and as students preparing for modern university life. Typically: 'because in the faculty we must discuss our opinions... because this task is aimed at the important things in our lives... we learn this type of writing how to express our opinions, we practice how to think about an issue...I like the different types of topics.... writing about our opinions is good for our future...I like the 2 tasks as how to range [arrange?] our ideas... it gives us experience and information in new topics and to improve the writing skills for faculty ... will help student in his academic life... and the almost inevitable 'it gives us useful words'.

Some responses identified that such writing helps improve independent thinking abilities; ' I will improve my thinking and now I have a good brain to think'. Such 'brain expansion' was associated with 'I learn how to bring support sentence', or, in other words perhaps, being able to elaborate and justify ideas in written form in another language gives the feeling of cognitive development. Other students specified similar areas; 'writing tasks make me explain my opinion, give reasons and support'. Another strongly agrees because 'its helping me by thinkful [to be thoughtful?] and trust myself'. Other comments:' [it] help me solve some questions.... It will help my reading and speaking'. In fact, over $80 \%$ of respondents signalled that this sort of writing task was beneficial because it helped them to 'think about a topic and to express my own opinion' and, significantly, 'depend on my idea'.

That the topics were not always relevant or interesting is seen in the following: "some topics I don't have to know about that subject [therefore not interesting or relevant] ...some topics are very bad and we can't say our opinion...Sometimes when I write a report for business I need to use supports and reasons, sometimes no because for business I need special style, not some topics boring and difficult'.

\section{What background knowledge do IELTS writing candidates need to have in order to pass the writing exam?}

Question 4: Apart from issues with vocabulary and grammar, what other issues may be a problem for IELTS students?

It is expected that, because the IELTS exam is now taken by candidates from over 170 countries, the rubric be as culture free and as international as possible. It follows that to respond fully to the questions the main issues (apart from the language ones of grammar and vocabulary) candidates ideally should be sufficiently engaged with contemporary world-wide social and cultural knowledge. Further, with the nature of the question being a personal opinion, some (relatively mature) personal reflection on and prior assessment of various issues come into the fore of a good written response.

Some teachers mentioned the usefulness of in-house timed writing questions relating to social, economic and educational issues in the UAE, as these 'situated' contexts could probably be adapted to many IELTS rubrics as well. One teacher mentioned that some/many students would not have the necessary socio-cultural experience to argue for, say, the freedom of the press; it is likely that some would not be ready for such a question, or on what are the characteristics of good or inferior journalism. There is a big leap, said a teacher, between some critical thinking about personal or local driving 
practices and critical thinking and critical writing about the pros and cons of developing nuclear energy. At the same time these questions were seen as 'common to L1 and L2 learners... becoming aware of the factors/issues is part of what we call education' and whatever socio-cultural background one has, being 19 years of age generally means perspectives have yet to mature. In addition, the 'pressure and push' of posing IELTS type questions may help break the habits of lower candidates of avoiding committing to suggest improvements. In other words, even though writing under such time constraints seems to be unlike most writing at university and indeed in life, the value of having an international writing exam to modify inadequate writing behaviour and to sharpen existing strengths was acknowledged strongly.

Another issue raised was of 'IELTS Anglo-centricity on occasions'; this may be a reference more to task 1 where, it seems, very few graphs reflect North American life.

\section{Does writing about IELTS Tasks 1 \& 2 encourage students to think and read more?}

Question 5: Writing about IELTS Tasks 1 \& 2 topics (themes in the IELTS Foundation text book include, Studying Abroad, Environment / managing traffic pollution, Tourism, Law and Punishment, Globalisation, Alternative medicine, Technological changes) encourages students to think and read more books, magazines, on the internet etc.

Table 5: Teachers' Views on IELTS writing topics and reading habits

\begin{tabular}{|l|l|l|l|l|l|l|}
\hline & $\begin{array}{l}\mathbf{1} \\
\text { Strongly } \\
\text { agree }\end{array}$ & $\mathbf{2}$ & $\mathbf{3}$ & $\mathbf{4}$ & $\mathbf{5}$ & $\begin{array}{l}\mathbf{6} \\
\text { Strongly } \\
\text { disagree }\end{array}$ \\
\hline $\begin{array}{l}\text { Number of } \\
\text { teachers } \\
(\mathbf{n = 1 6 )}\end{array}$ & 1 & 6 & 3 & 2 & 2 & 2 \\
\hline
\end{tabular}

\section{(a) Teachers' views}

Respondents' reactions ranged from the optimistic 'I think that if students are exposed to some of these ideas which are outside their normal pattern of thought it just might stimulate them to further research, to the more pessimistic: 'students are not motivated to read their own...there is no reading culture in the university...I've yet to see any evidence of serious reading...My students are only interested in cars, mobile phones and football... it would have to be a specific homework task to get them to look at anything else...I've only seen one young local reading a book outside of class once in 10 years...They might discuss topics more, or think of them or read articles they stumble on in newspapers maybe...Most of our students would rather not read at all, especially about things not related to their coursework'.

In brief, those who are really motivated and interested will read more widely, others not. It might not be that the exam 'encourages' such reading, but it might mediate it or at least facilitate it was another nuanced response. 'Students appear to read little in English outside of their reading requirements (in class), therefore any and all stimulation in the direction of finding out what is topical and relevant is advantageous for them...By providing such a cut and dried benchmark student 'will read around these topics if they want to pass bad enough'.

The variation of a student's reading interest being influenced by a teachers' interests is reflected in this comment 'In general these topics are interesting to me and so I might motivate students to extend their reading outside of class more than another'. 
(b) Student views: Does the IELTS curriculum /exam result in more reading?

Question 6: Because I want to be prepared for the "IELTS topics" I try to read more about them in newspapers, magazines, internet'. Agree / disagree?

Table 6: Do students read more?

\begin{tabular}{|l|l|l|l|l|l|l|}
\hline & $\begin{array}{l}1 \\
\text { Strongly } \\
\text { agree }\end{array}$ & $\mathbf{2}$ & $\mathbf{3}$ & $\mathbf{4}$ & $\mathbf{5}$ & $\mathbf{6}$ \\
\hline $\begin{array}{l}\text { Number of } \\
\text { students } \\
\text { (n=35) }\end{array}$ & 14 & 7 & 8 & 5 & 0 & $\begin{array}{l}\text { Strongly } \\
\text { disagree }\end{array}$ \\
\hline
\end{tabular}

The high proportion of students reporting reading outside of the classroom is a contrast to the perceptions of teachers. While it is likely that some students have over-reported their reading habits it is also possible that teachers underestimate the powerful motivation a high-stakes exam has. At the very least it suggests that students know that to have an adequate vocabulary, grammar and background knowledge to write well they do need to read widely and thoughtfully: 'I agree because...the IELTS topics is about a common and important issues in the society...because this helps you not only in your faculty studies but also in the IELTS exam...I think they will help me in my life more than my studies because they make me aware of a lot of things... it improves my English language... because it's good to read of things outside my country...but we don't have a lot of magazines or newspapers with English... to grow my vocabulary...it will help the students' culture...I like to read newspapers and to get new topics and vocabulary for myself in my life and for my faculty [i.e. not necessarily because for IELTS]...yes I should know more about them". The value of the habit of consolidating classroom reading at regular intervals is revealed in this comment: "when I see [these ideas again] they improve me more fastly...I remember class book ideas and words...it's a good habit for all students'.

The disagree comments again came from those who saw no relationship with writing about such generic and global topics ('why the faculty of sharia and law study English? We don't need it') or from resistant readers: 'I don't do extra reading because I don't like to read a lot...no I never read English newspapers or magazines...').

\section{Will doing the IELTS preparation course and exam help me with faculty studies?}

\section{Students' Views}

Question 6: The writing topics in your Level 3 / IELTS preparation class (such as in your IELTS Foundation text, e.g. Studying Abroad, The Earth's Environment, Tourism, Law and Punishment, Globalisation, Alternative Medicine, Technology'), will help you in your faculty studies. Agree or disagree?

Table 7: Students views on whether IELTS/L3 writing topics will help at faculty

\begin{tabular}{|l|l|l|l|l|l|l|}
\hline & $\begin{array}{l}\mathbf{1} \\
\text { Strongly } \\
\text { agree }\end{array}$ & $\mathbf{2}$ & $\mathbf{3}$ & $\mathbf{4}$ & $\mathbf{5}$ & $\begin{array}{l}\mathbf{6} \\
\text { Strongly } \\
\text { disagree }\end{array}$ \\
\hline $\begin{array}{l}\text { Number of } \\
\text { students } \\
(\mathbf{n = 3 6 )}\end{array}$ & 14 & 5 & 3 & 7 & 2 & 2 \\
\hline
\end{tabular}


\begin{tabular}{|l|l|l|l|l|l|}
\hline & & & & & \\
\hline
\end{tabular}

The disagree comments seemed to arise from the desire to study their faculty subjects rather than write about these more general topics, perhaps indicating that research-based writing is more relevant for this group: 'I disagree because in the faculty there will be other topics and that depends on our major...in law I don't use English...strongly disagree because everyone wants to study his faculty topics... because it's boring and don't help me about topics in business...'.

It is notable that the clear majority held some value to writing about the given topics, not only for usefulness at faculty but also in their own lives: 'I agree because sometimes it helps me... these topics help student to [come up with] ideas... yes these topics are important in university... because of wide range of topics and new knowledge...I think that they will help me in my life more than my studies because they make me aware of a lot of things... new words [from the topics] will help the student... will help in our life...I can show the chart in my work...they are good topics for us, they are necessary in our life...'.

\section{Do teachers think that overall IELTS has a positive or negative impact on UGRU writing?}

Question 7: Overall, how would you describe the impact of IELTS on writing at UGRU? Positive or negative?

Table 8: Teachers' views of IELTS"S impact on UGRU Writing

\begin{tabular}{|l|l|l|l|l|l|l|}
\hline & $\begin{array}{l}\mathbf{1} \\
\text { Positive }\end{array}$ & $\mathbf{2}$ & $\mathbf{3}$ & $\mathbf{4}$ & $\mathbf{5}$ & $\mathbf{6}$ \\
\hline $\begin{array}{l}\text { Number of } \\
\text { teachers } \\
(\mathrm{n}=15)\end{array}$ & 5 & 6 & 0 & 2 & 2 & 0 \\
\hline
\end{tabular}

The few negative statements (made in the 'focus group' and in questionnaire) included that it may 'restrict creativity' for some students and it has narrowed the syllabus: 'It's made our curriculum more like 'test preparation' rather than academic preparation - many students who barely make it through still require intensive review and practice before meeting faculty level expectations'. One teacher saw it as overall negative because the types of skills, especially task 1 are most likely not used again outside of UGRU...the impact is significant, the [writing] course is starting to resemble an IELTS prep course. I would prefer to see some thematic test which places the student more in the expected context'.

Overall, though, the teachers in this small sampling saw IELTS as having a positive impact on the programme and student learning. Some staff were positive because of the opportunity if gives both students and staff for international and university benchmarking. 'It's good as a benchmark and to help us aim for international standards...It's the best exam of its kind, better than TOEFL...Just that exams are one way of sampling, therefore can't be $100 \%$ accurate...students are motivated by having to pass IELTS... students are required to analyse more... IELTS is a confidence building experience as it's an international exam... [where an education culture is still being built] students respond to the 'need' to study and IELTS forces many to take note, be aware, practice etc...provides a concrete goal...It introduces students to meaningful academic-like writing tasks... encourages students to hone their writing skills'. 


\section{Conclusions}

Overall, this small-scale study found a strong overlap between what the IELTS writing tasks required and what students and staff thought was needed in a writing course. Teachers considered the writing exam to be a reasonable and appropriate direct communicative performance test. Task 1 was seen as particularly salient because the required skills (identifying, summarizing and highlighting) of an information transfer bear a close relationship with many faculty level (and workplace) writing tasks. While the genre of task 2 was not seen to have such a direct bearing on faculty writing types ('too general' and 'not research based') the necessary writing and thinking skills were. In other words, even though differences between the IELTS and University writing tasks were commented upon, the IELTS tasks were seen to suitably guide teaching emphases and to push students' writing output using the necessary skills.

In conducting the study I was surprised by the responses for two reasons. As a classroom writing teacher, being so immersed in the teaching, I had not fully understood the students' perspectives. I had interpreted sometimes hesitant writing output, and difficulty to produce at a high level in exam conditions, perhaps as signs of resistance to the exam itself. Student responses, in fact, revealed a clear understanding of the usefulness of an exam not just as a 'hoop to jump through' but as an instrument for mediating growth in thinking across a range of globally relevant topics. Similarly, I had expected fellow teachers to express more tension between the demands of teaching to the writing test and wider writing activities and alternative assessments such as producing portfolios. It is notable that the respondent who said that the course had become a 'teach to the exam course' nevertheless commented that the exam was suitable for a university preparation course: "Washback is almost invariably seen as negative..., [but] learning for the test is only bad learning if the test is bad" (as cited by Davidson \& Mandalios; from Biggs, 1999). In fact, none of the respondents felt the exam was bad. Even though it is possible for the type of impact to be independent of the quality of the exam - that is, a good test might have bad consequences (and conversely a bad writing test have a positive impact) - the teachers and students in this study suggest that the writing exam, and its preparation are instrumental in facilitating a valid focus on improving writing and thinking skills. Because the IELTS focus is an integral part of the whole university preparation learning experience, with plentiful material and teacher support, and not something 'bolted on', it is probable that this helps explain some of the positive reported attitudes towards the exam.

This study suggests then that, given both the linguistic and thinking skills necessary to demonstrate writing competency, preparing university students for IELTS writing is likely to contribute to meeting the espoused educational and societal goals of the state university. Such aims are likely to be reinforced with the introduction (in May 2007) of two similar task types (and rating criteria) in the UAE nationwide Common Educational Placement Assessment (CEPA) English exam for all year 12 students. However, only further research on the actual outcomes will determine more clearly the extent which the IELTS writing exam has created an impetus for beneficial changes in preparing students for university and beyond.

\section{References}

Al Belehi (2006). Structure of Retardardation in the Arab Mind. Gulf News, September 28, 2006. http://archive.gulfnews.com/nation/Society/100070994.html . 
Alderson, C. \& Hamp-Lyons, L. (1996). TOEFL Preparation Courses: a Study of Washback. Language Testing 13(3): 280-297.

Chapman, D. \& Snyder, C. (2000). Can high stakes national testing improve instruction: reexamining conventional wisdom. International Journal of Educational Development 20(6): 457-474.

Cheng, L. (1997). How does washback influence teaching? Implications for Hong Kong. Language and Education, Volume 11, Number 1, 1997

Cheng, L. Watanabe, \& Y. Curtis, A. (2004) (eds.). Washback in Language Testing: Research Contexts and Methods. Lawrence Erlbaum and Associates: New York.

Clapham, C. (1996). Studies in Language Testing 4. The Development of IELTS: A study of the effect of Background on Reading Comprehension. Cambridge University Press: Cambridge.

Coleman, D. Starfield, \& S. Hagan, A. (2003). The attitudes of IELTS stakeholders: student and staff perceptions at Australian, UK and Chinese tertiary institutions. IELTS Research Reports, 2003, Volume 5, Paper 4.

Davidson, P. \& Mandalios, J. (2005). Using Assessment to Facilitate Learning. Presentation given at the $9^{\text {th }}$ CTELT Conference, Dubai, United Arab Emirates.

Davies, A. (2007). Assessing Academic English: Testing English Proficiency, 1950-1989 - the IELTS solution. Studies in Language Testing Series ed. Milanovic, I. \& Weir, C. Cambridge University Press / Cambridge ESOL Examinations: Cambridge.

Green, A. (2007). IELTS Washback in Context: Preparation for Academic writing in higher education. Studies in Language Testing Series ed. Milanovic, I. \& Weir, C. Cambridge University Press / Cambridge ESOL Examinations: Cambridge.

IELTS Scores Explained (2006). DVD. Information available at http://www.ielts.org/mediacentre/article341.aspx

IELTS (2007). IELTS Joint-funded research program 2007/2008. Retrieved 12 June 2007 from <http://www.ielts.org/teachersandresearchers/grantsandawards/article250.aspx>.

Merrylees, B. (2003). An impact study of two IELTS user groups: candidates who sit the test for immigration purposes and candidates who sit the test for secondary education purposes. IELTS Research Reports. 2003, Volume 4, Paper 1

Moore, T. \& Morton, J. (1999). Authenticity in the IELTS Academic Module Writing Test: a comparative study of task 2 items and university assignments. 1999, IELTS Research Reports. Volume 2.

Read, J. \& Hayes, B. (2003). The impact of IELTS on preparation for academic study in New Zealand. IELTS Research Reports Volume 4, 153-206.

Spratt, M. (2005). Washback and the classroom: the implications for teaching and learning of studies of washback from exams." Language Teaching Research 9,1: 5-29.

\section{Author}

The author is currently an IELTS Examiner Trainer at the UAE University and teaching in the preparatory (UGRU) writing programme. Has trained and worked as a high school and ESL teacher in his native New 
Zealand as well as various European countries; he has also worked as a university counsellor \& chaplain for a number of years.

Lewthwaite, M.D. (2007). Teacher and Student Attitudes to IELTS Writing Tasks: Positive or Negative Washback?. Learning and Teaching in Higher Education: Gulf Perspectives 4(2). 


\section{Appendix 1}

\section{Questionnaire: Impact of IELTS Writing preparation and Exam}

(teachers)

This questionnaire is aimed to get some comments on your views about the usefulness and impact of the two IELTS writing tasks (a) for assessing a students readiness for English medium writing at faculty level (b) in promoting certain writing skills needed at university level.

Information about IELTS Writing Tasks $1 \& 2$ is available here:

http://www.ielts.org/candidates/findoutmore/freesamples/article330.aspx

I will ensure your anonymity / non-identifiability in any reported comments. The study is for an academic project only.

Thanks very much for your help

[author's name] - UAEU - UGRU (Mobile 050 7331864)

Please respond to the following 7 questions / statements:

Q1: IELTS Task 1 asks candidates to summarise a graphic (chart, table, flow chart etc). I agree/disagree there is a reasonable correspondence between the skills needed for this, and needed for writing requirements at faculty level.

Strongly agree

1

Comment:
Strongly disagree

5

Q2: Task 2 asks candidates to argue a point of view ('to what extent do you agree or disagree') or outline advantages and disadvantages with some social, environmental, technological / value position.. I agree / disagree that there is a reasonable correspondence between the skills needed for this and for faculty writing tasks. \{Consider that IELTS candidates need to discuss issues, construct an argument with plentiful ideas and evidence and use the appropriate tone and register).

Strongly agree

1

Comment:
3 strongly disagree

5

Q3: What similarities and / or differences can you see between the IELTS timed writing tasks (and preparation for) and writing tasks at faculty level. (e.g IELTS timed writing Task 2 requires more prior knowledge than many University writing tasks such as research assignments)

Lewthwaite, M.D. (2007). Teacher and Student Attitudes to IELTS Writing Tasks: Positive or Negative Washback?. Learning and Teaching in Higher Education: Gulf Perspectives 4(2). 
Q4: Apart from issues with vocabulary and grammar what other issues may be a problem for IELTS candidates (ie imagined audience, impact of socio-cultural experience on the interpretations of the prompts...):

Q5: What is the best way to assess a students' readiness for managing writing tasks at faculty level? (a) IELTS based timed writing tests (b) a writing portfolio (c) a combination of both? (d) other Why?

Q6: Writing about IELTS Task $1 \& 2$ topics encourages students to think and read more about them in books, newspapers, magazines, on the internet etc

Strongly agree

1

2
3
4

\section{Strongly disagree}

5

\section{6}

Why?

Q7: Overall, how would you describe the impact of IELTS writing tasks at UGRU level on students writing at faculty level?

\section{Positive}

1

Why?
2

3
4
Negative

Any other comments welcome:

Lewthwaite, M.D. (2007). Teacher and Student Attitudes to IELTS Writing Tasks: Positive or Negative Washback?. Learning and Teaching in Higher Education: Gulf Perspectives 4(2). 


\section{Questionnaire: Impact of IELTS Writing preparation and Exam}

\section{(student version)}

This questionnaire is aimed to get some comments on your views about the usefulness and impact of the two IELTS writing tasks (a) for assessing a students readiness for English medium writing at faculty level (b) in promoting certain writing skills needed at university level.

More information about IELTS Writing Tasks $1 \& 2$ is available here:

http://www.ielts.org/candidates/findoutmore/freesamples/article330.aspx

Thanks very much for your help

Malcolm Lewthwaite - UAEU - UGRU (Mobile 050 7331864)

Please respond to the following 7 questions / statements:

Q1: IELTS Task 1 asks candidates to summarise a graphic (chart, table, flow chart etc). I agree/disagree this will be a useful writing skill at faculty level.

Strongly agree

1

Comment:
Strongly disagree

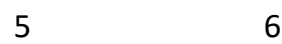

Q2: Task 2 asks candidates to argue a point of view ('to what extent do you agree or disagree') or outline advantages and disadvantages with some social, environmental, technological / value position.

Lewthwaite, M.D. (2007). Teacher and Student Attitudes to IELTS Writing Tasks: Positive or Negative Washback?. Learning and Teaching in Higher Education: Gulf Perspectives 4(2). 
I agree / disagree that this is a useful skill at faculty level.

Strongly agree

strongly disagree

1

2

3

4

5

6

Comment:

Q3: What similarities and differences can you see between the IELTS timed-writing tasks (and preparation for) and writing tasks at faculty level.

Q4: Do you agree or disagree that the topics in your IELTS Foundation book are useful subjects to write about as preparation for studies at university?

(the topics include Studying Abroad - culture shock, Environmental issues, Tourism, Styles of learning, Work, Law, Crime \& punishment, Globalisation, Alternative medicine, Technology (Robots, computing), Advertising)

Strongly agree

1

2

3
Strongly disagree

5

6

Are some topics not suitable do you think?

Q5: What is the best way to assess a students' readiness for managing writing tasks at faculty level? (a) IELTS based timed writing tests (b) a writing portfolio (c) a combination of both? (d) other

Why? 
Q6: Writing about IELTS Task 1 \& 2 topics encourages me to think and read more about them in books, newspapers, magazines, on the internet etc

Strongly agree

1

2

3

4
Strongly disagree

5

6

Why?

Thank you for taking the time to respond to this survey

Malcolm Lewthwaite

UAEU-UGRU Communications/English 